\section{Isolation and Characterization of Apolipoprotein B-48 and B-100 Very Low Density Lipoproteins from Type III Hyperlipoproteinemic Subjects}

\author{
Ross W. Milne, Philip K. Weech, Louise Blanchette, \\ Jean Davignon, Petar Alaupovic, and Yves L. Marcel \\ Laboratory of Lipoprotein Metabolism, Clinical Research \\ Institute of Montreal, Quebec H2W IR7, Canada; Laboratory of \\ Lipid and Lipoprotein Studies, Oklahoma Medical Research \\ Foundation, Oklahoma City, Oklahoma 73104
}

A lipoprotein (apo) B have been identified, apo B-48 and apo B-100, which are the predominant forms in chylomicrons and very low density lipoproteins (VLDL), respectively. Due to defective hepatic clearance, apo B-48 containing lipoproteins accumulate in the plasma of subjects with type III hyperlipoproteinemia. In the present study, we have used immunoaffinity chromatography to separate type III VLDL into a nonretained (apo B-48 VLDL) and a retained (apo B-100 VLDL) fraction. To achieve complete separation, as determined by electrophoresis and radioimmunoassay, it was necessary to employ two different insolubilized anti-apo B-100 monoclonal antibodies because of immunochemical heterogeneity within the apo B-100 VLDL fraction. The ability to separate apo B-100 VLDL from apo B-48 VLDL shows that the two apo $B$ species are found on different particles. The apo B-48 VLDL had an electrophoretic mobility similar to chylomicrons, whereas the apo B-100 VLDL migrated similarily to total type III VLDL. Both fractions showed a concentration of particles with diameters $\sim 100$ $\mathrm{nm}$, with apo B-48 VLDL being somewhat more heterogeneous in particle size. The two fractions were qualitatively similar in apolipoprotein composition but apo B-48 VLDL was enriched in apo E, relative to apo B-

Dr. Milne is a scholar of the Fondation de la Recherche en Santé du Québec.

Received for publication 27 March 1983 and in revised form 7 September 1983.

J. Clin. Invest.

(c) The American Society for Clinical Investigation, Inc.

0021-9738/84/03/0816/08 $\$ 1.00$

Volume 73, March 1984, 816-823
100 VLDL. Apo B-48 VLDL was enriched in cholesterol esters and deficient in triglycerides and phospholipids when compared with apo B-100 VLDL. The existence of immunochemical heterogeneity in the apo B-100 VLDL may reflect different functional subpopulations of particles within this fraction.

\section{Introduction}

Substantial attention has been given to lipoprotein disorders of subjects with type III hyperlipoproteinemia, despite the comparative rarity of this phenotype among subjects with familial hyperlipidemias. The clinical characteristics of familial type III hyperlipoproteinemia have been reviewed (1) and include a high incidence of premature peripheral and coronary artery disease, lipid deposition in tissues, especially in the form of tuberous xanthomas and planer xanthomas in creases, rapid normalization of the hyperlipidemia following simple treatment, and several typical lipoprotein abnormalities. The lipoprotein abnormalities are themselves threefold: $(a)$ a dysbetalipoproteinemia that presents itself as a noticeable quantity of very low density lipoprotein (VLDL) with $\beta$-electrophoretic mobility, cholesterol-enriched VLDL, abnormalities in the $\mathrm{E}$ apoprotein (2-5), and an elevated plasma apolipoprotein (apo) E concentration (6); (b) a hyperlipidemia that may be inherited (familial combined hyperlipidemia) or acquired (hypothyroidism) independently of the mutant apo $E$ gene that may be superimposed on the dysbetalipoproteinemia $(7,8)$; and $(c)$ an overproduction of apo B is concurrent with the hyperlipidemia peculiar to hyperlipidemic dysbetalipoproteinemia, with a greater-than-proportional overproduction of apo B in an otherwise minor $(\beta)$ pathway in the VLDL, and direct input into the intermediate density lipoprotein (IDL) $(9,10)$. Other factors, including age and obesity, may also play a role in the expression of the type III phenotype.

1. Abbreviation used in this paper: apo, apolipoprotein. 
In recent years it has become evident that human apo $B$ is chemically and physically heterogeneous. The principal species of apo B in normal human VLDL and low density lipoprotein (LDL) has an apparent molecular weight in sodium dodecyl sulphate (SDS) of 549,000 and has been termed apo B-100 in a centile system of nomenclature based on molecular weight. The predominant apo B form in human chylomicrons, apo B48 , has a molecular weight of 264,000 and is not found in normal LDL (11). The amino acid composition of apo B-48 is different from that of apo B-100 (11) although immunological cross-reactivity exists between the two species $(12,13)$. There is evidence to suggest that the synthesis of apo B-100 and apo B-48 is under separate genetic control (14). Two recent reports $(15,16)$ have described the presence of apo B-48 in the VLDL of subjects with familial type III hyperlipoproteinemia.

We have described the production and characterization of a series of monoclonal antibodies against human apo B-100 $(12,17,18)$. Of seven anti-apo B-100 antibodies, five did not react with apo B-48. Here we describe the use of some of these monoclonal antibodies for the separation of VLDL from type III hyperlipoproteinemic patients into two fractions that contain either apo B-48 or apo B-100 as their sole apo B proteins. We show that the apo B-48 and apo B-100 are on different lipoprotein particles and that the two VLDL subfractions differ in their physicochemical properties. This study furthermore demonstrates that there is immunochemical heterogeneity in apo B expression within the apo B-100 containing VLDL.

\section{Methods}

Experimental subjects. The plasma used for these studies was derived from eight subjects (seven males) with the E2/2 apo E phenotype as determined by the technique of Bouthillier et al. (19). The diagnosis of type III dysbetalipoproteinemia had been established at a prior visit at the lipid clinic on the basis of elevated plasma cholesterol (>250 mg/ dl) and/or elevated plasma triglycerides ( $>200 \mathrm{mg} / \mathrm{dl}$ ) with one or more of the following characteristics of type III: typical skin xanthomas, a broad betaband, the presence of $\beta$-VLDL, a VLDL-cholesterol/triglyceride ratio of 0.30 or more, or equally high levels of plasma cholesterol and triglycerides. A large amount of plasma from one patient whose cholesterol was $345 \mathrm{mg} / \mathrm{dl}$ and triglycerides were $404 \mathrm{mg} / \mathrm{dl}$ at the time of sampling was used for all the studies used to validate the separation technique. Plasma samples from the other seven patients were pooled for all the analytical studies.

Preparation of lipoproteins. Blood from normal subjects or patients with type III hyperlipoproteinemia was collected after a 14-h fast into EDTA and the red blood cells were removed by centrifugation. Lipoprotein fractions were prepared by floatation in a Beckman L5-65 ultracentrifuge (Beckman Instruments, Inc., Spinco Div., Palo Alto, CA) with a $50.2 \mathrm{Ti}$ rotor at $5^{\circ} \mathrm{C}, 45,000 \mathrm{rpm}$ for $20 \mathrm{~h}$. LDL were isolated from normal subjects by successive ultracentrifugation (20) at $4^{\circ} \mathrm{C}$ between densities of 1.030 and $1.050 \mathrm{~g} / \mathrm{ml}$. The VLDL and IDL from type III hyperlipoproteinemic subjects were isolated at densities of 1.006 $\mathrm{g} / \mathrm{ml}$ and of $1.006-1.019 \mathrm{~g} / \mathrm{ml}$, respectively. The lipoprotein subfractions were dialyzed against phosphate-buffered saline (PBS) containing $1 \mathrm{mM}$ EDTA and $0.02 \% \mathrm{~N}_{3} \mathrm{Na}$ and stored at $4^{\circ} \mathrm{C}$.
Monoclonal antibodies and antisera. Monoclonal antibodies against human apo B have been reported $(12,17)$. Affinity-purified rabbit antimouse IgG was purchased from Kirkegaard and Perry Laboratories, Inc. (Gaithersburg, MD). The preparation of antisera used in the electroimmunoassays are described in the relevant reference for each apolipoprotein assay.

Immunoadsorbants and affinity chromatography. The IgG was precipitated from the ascitic fluid of mice bearing the hybridomas $4 \mathrm{G} 3$ or $5 E 11$ with $40 \%$ saturated ammonium sulphate. The precipitated protein was redissolved in and dialyzed against $0.1 \mathrm{M}$ sodium bicarbonate, $\mathrm{pH}$ 8. Activation of Sepharose 4B (Pharmacia Fine Chemicals, Inc., Uppsala, Sweden) and the coupling of $200 \mathrm{mg}$ protein $(5 \mathrm{mg} / \mathrm{ml})$ to $50 \mathrm{ml}$ of activated Sepharose $4 \mathrm{~B}\left(16 \mathrm{~h}\right.$ at $4^{\circ} \mathrm{C}$, with agitation) were carried out according to March et al. (21). In all experiments, $<5 \%$ of the protein remained unbound. The Sepharose was saturated with $1 \mathrm{M}$ glycine ( $\mathrm{pH}$ 8.5) overnight at $4^{\circ} \mathrm{C}$ and then subjected to alternating washes of 0.1 $\mathrm{M}$ sodium acetate $(\mathrm{pH} 4)$ and $0.1 \mathrm{M}$ sodium carbonate $(\mathrm{pH} 8.5)$.

Varying amounts of VLDL or IDL isolated from type III plasma were applied to $8-\mathrm{ml}$ columns of either $4 \mathrm{G} 3$ or $5 \mathrm{E} 11$ Sepharose. The columns were washed with $0.015 \mathrm{M}$ PBS (pH 7). Bound lipoproteins were eluted with $0.05 \mathrm{M}$ citric acid containing $1 \mathrm{M} \mathrm{NaCl}(\mathrm{pH} 2.5)$. The eluted fraction was immediately dialyzed against $0.015 \mathrm{M}$ PBS containing $0.02 \% \mathrm{~N}_{3} \mathrm{Na}$ and $0.01 \%$ EDTA.

Radioimmunoassay (RIA) of apo $B$. The sample to be tested, diluted in $1 \%$ bovine serum albumin in PBS (buffer A) was incubated overnight at $4^{\circ} \mathrm{C}$ with an equal volume of an appropriately diluted monoclonal anti-apo B (2D8 1/3 × 10 $\left.0^{6}, 4 \mathrm{G} 31 / 10^{5}, 5 \mathrm{E} 111 / 10^{5}\right)$. LDL $(200 \mu \mathrm{l})$ at $30 \mu \mathrm{g}$ protein $/ \mathrm{ml}$ in $5 \mathrm{mM}$ glycine, $\mathrm{pH} 9.2$ (buffer B), was added to Removawells (Dynatech Laboratories, Inc., Alexandria, VA), and left overnight at room temperature. The following day the wells were washed in $0.15 \mathrm{M} \mathrm{NaCl}$ containing $0.025 \%$ Tween 20 (buffer $\mathrm{C}$ ) and then exposed for $30 \mathrm{~min}$ at room temperature to $300 \mu \mathrm{l}$ of buffer $\mathrm{A}$ to saturate the plastic. $200-\mu \mathrm{l}$ aliquots of the sample-antibody mixtures were added to the wells and left for $24 \mathrm{~h}$ at room temperature. The wells were washed in buffer $C$ and $250 \mu \mathrm{l}$ of ${ }^{125} \mathrm{I}$-anti-mouse IgG diluted in buffer $A$ was added to the wells. After an overnight incubation the wells were washed as described above and the bound radioactivity was determined. Results are expressed as $\mathrm{B} / \mathrm{Bo}$, where $\mathrm{B}=\mathrm{cpm}$ bound $-\mathrm{cpm}$ nonspecifically bound and $\mathrm{Bo}=\mathrm{cpm}$ bound in the absence of sample - cpm nonspecifically bound. Nonspecific binding was determined in wells in which the sample was replaced by LDL diluted to $100 \mu \mathrm{g}$ protein $/ \mathrm{ml}$. The intraassay coefficient of variation for the measurement of VLDL was $10 \%$.

Quantitative determination of apolipoprotein. The quantitative determination of VLDL-associated apoproteins was carried out by previously described procedures for apoproteins A-I and A-II (22), B (23), C-I (24), C-II (24), C-III (25), and E (6).

Lipid analysis. From pooled VLDL prepared from type III patients we took samples of VLDL, apo B-48 VLDL, and apo B-100 VLDL fractions estimated to contain $\sim 200 \mu \mathrm{g}$ protein. After lyophilizing these samples, the procedures described by Kuksis et al. (26) were used for digestion with $0.3 \mathrm{mg}$ phospholipase C (Sigma Chemical Co., St. Louis, MO), followed by addition of $200 \mu \mathrm{g}$ tridecanoyl glycerol (Serdary Research Laboratories, London, Ontario, Canada) as internal standard, and extraction of the lipids. The dried extract was redissolved in $80 \mu \mathrm{l}$ pyridine and derivatized with $20 \mu \mathrm{l} N, \mathrm{O}$-bis-(trimethylsilyl)-trifluoroacetamide (BSTFA; Pierce Chemical Co., Rockford, IL). The lipid-silyl ethers were analyzed by chromatography on $3 \% \mathrm{OV}-1$ in a single glass column $(600 \times 2 \mathrm{~mm})$ using a Hewlett-Packard model 5880 gas chromatograph (Hewlett-Packard Co., Palo Alto, CA) with level 4 terminal, 
in the single-column compensation mode. The temperature program $\left(4^{\circ} \mathrm{C} / \mathrm{min}\right)$ was identical to that of Kuksis et al. (26); the column was primed by repeated injections of a serum lipid extract or triglycerides, and was calibrated with the following standards: monopalmitoyl glycerol, dipalmitoyl glycerol, tripalmitoyl glycerol, trioleoyl glycerol, unesterified cholesterol, cholesteryl palmitate (Hormel Institute, Austin, MN), cholesteryl stearate (K and K Laboratories, Inc., Plainview, NY), and unesterified cholesterol (Serdary Research Laboratories). The amount of each lipid was calculated using Eqs. 1 and 2 of Kuksis et al. (26) from the integrator peak areas. A factor 1.28 was used to estimate the quantity of phospholipid from the amounts of diacylglycerols and ceramides found.

Lipoprotein analysis. The apolipoprotein composition of the VLDL subfractions was assessed by SDS (27) and tris-urea (28) polyacrylamide gel electrophoresis. To identify apo B-100 and apo B-48 in type III VLDL and its subfractions, SDS polyacrylamide gel electrophoresis was carried out according to Kane et al. (11). Paper electrophoresis in an albumin-containing buffer was performed according to Lees and Hatch (29). For electron microscopy, samples were negatively stained with potassium phosphotungstate (30) and the diameters of particles were measured directly on the calibrated positive plates. Protein concentration was measured by the Lowry technique (31).

\section{Results}

Capacity of anti-apo B-100 immunoadsorbants. Two monoclonal antibodies, 4G3 and 5E11 $(12,17)$, were chosen on the basis of their lack of cross-reactivity against apo B-48. The IgG fractions, partially purified from the ascitic fluids of mice bearing the hybridomas $4 \mathrm{G} 3$ and 5E11, were covalently coupled to Sepharose. To determine the capacity of the two immunoadsorbants, $0.5 \mathrm{ml}$ of LDL $(2 \mathrm{mg} / \mathrm{ml})$ was incubated at room temperature for $2 \mathrm{~h}$ with $200 \mu \mathrm{l}$ of Sepharose-bound 4G3, 5E11, or normal mouse IgG, and the protein concentration of the unbound fraction was determined. Under these saturating conditions the respective capacities for the $4 \mathrm{G} 3$ and 5E11 Sepharose were 1.2 and $2.5 \mathrm{mg} \mathrm{LDL}$ protein/ml Sepharose. In the case of Sepharose-bound normal mouse IgG, virtually all (96-105\%) of the LDL was recovered in the nonretained fraction. Although their capacities diminished with repeated usage, the immunoadsorbant columns could be used $\sim 20$ times.

Isolation of apo B-48 containing lipoproteins from type III $V L D L .2 \mathrm{ml}$ of VLDL ( $5 \mathrm{mg}$ protein) isolated from a patient with type III hyperlipoproteinemia was passed on an 8-ml column of 5E11 Sepharose. The starting VLDL and the nonretained and retained fractions were tested in RIA using the antibodies 4G3 and 5E11 as well as 2D8, an antibody that cross-reacts with apo B-48. As expected, both the retained and nonretained fractions competed with LDL for the antibody 2D8 (Fig. 1). The fraction nonretained by $5 \mathrm{E} 11$ showed little reactivity in RIA with $5 E 11$ but could compete quite efficiently with LDL for $4 \mathrm{G} 3$. Similar results were observed with IDL from the same patient (not shown).

This would suggest that either the capacity of the column was exceeded, or antigenic heterogeneity existed in the spectrum of lipoprotein particles containing apo B-100. To test this, type III VLDL (5 mg protein) was passed on 5E11 Sepharose, the

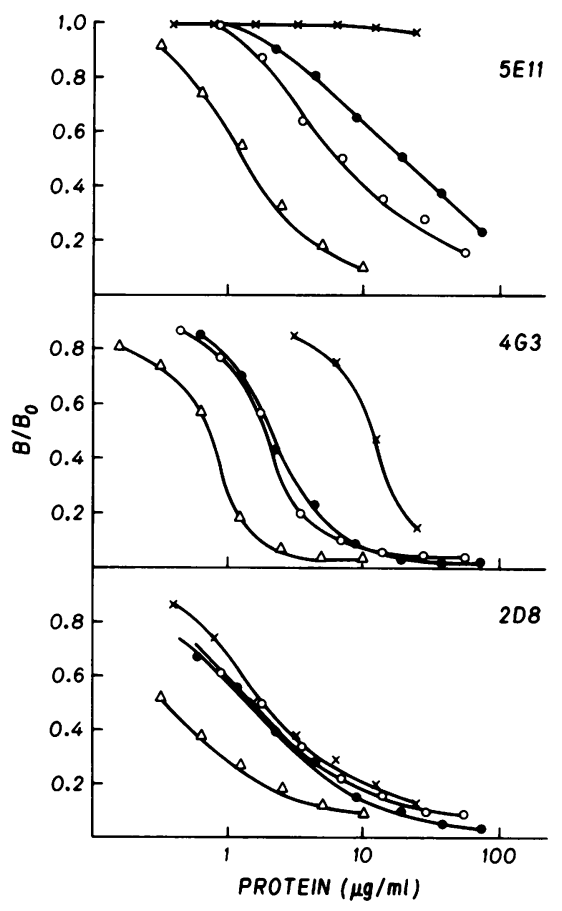

Figure $1.5 \mathrm{mg}$ of type III VLDL was passed on 5E11 Sepharose. The starting VLDL ( $\bullet$ ), the nonretained fraction $(x)$, the retained fraction (eluted with acid) (0), as well as normal LDL $(\Delta)$ were tested in RIA using either antibodies $5 \mathrm{E} 11$ or $4 \mathrm{G} 3$, which react only with apo B-100, or 2D8, which reacts with both apo B-100 and apo B-48.

nonretained fraction was divided in two and either passed on 4G3 Sepharose or repassed on 5E11 Sepharose. The nonretained fractions were tested in RIA against 2D8, 4G3, and 5E11 (Fig. 2). Passage on $4 \mathrm{G} 3$ Sepharose of the fraction not retained by $5 E 11$ removed almost all activity against $4 G 3$, whereas repassage on 5E11 had little effect. Passage of type III VLDL directly on 4G3 Sepharose resulted in a nonretained fraction which showed $\sim 1.5 \%$ of the starting activity in RIA with $4 \mathrm{G} 3$ and $8 \%$ of the starting activity with 5E11 (not shown).

SDS-polyacrylamide gel electrophoresis of the fractions bound and unbound (Fig. 3) confirmed the results of the RIA. A single passage of type III VLDL on 5E1 1 Sepharose selectively removed a portion of the apo B-100. Repassage of the nonretained fraction on 4G3 Sepharose but not on 5E11 Sepharose removed almost all of the remaining apo B-100. No apo B-48 was detected in the 5E11-retained fraction. Three subsequent experiments with a similar protocol have yielded the same results.

These results suggested that, if care were taken to not overload the columns, apo B-48 VLDL could be prepared free of apo B100 VLDL by sequential passage on $5 E 11$ and $4 \mathrm{G} 3$ immunoadsorbants. Thus, when $2 \mathrm{mg}$ of type III VLDL was applied sequentially to the 5E11 and 4G3 Sepharose, the nonretained fraction contained no apo B-100 VLDL, and no apo B-48 VLDL was present in the retained fraction (Fig. 4). The lack of apo B-100 in the nonretained fraction was confirmed in RIA against 


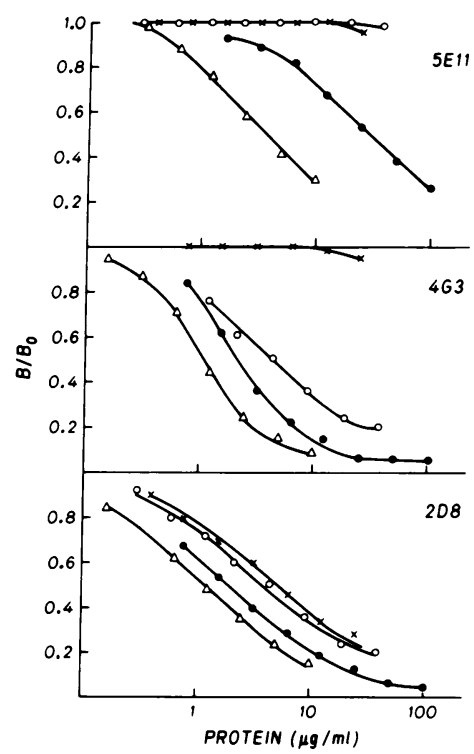

Figure $2.5 \mathrm{mg}$ of type III VLDL was passed on 5E11 Sepharose. The nonretained fraction was divided into two and repassed on either 5E11 Sepharose or 4G3 Sepharose. The starting $\operatorname{VLDL}(\bullet)$, the fractions not retained following repassage on 5E11 Sepharose (O) or 4G3 Sepharose $(x)$, respectively, and normal LDL $(\Delta)$ were tested in RIA using antibodies $5 E 11$ or $4 \mathrm{G} 3$, which react unly with apo B-100, or D8, which reacts with both apo B-48 and apo B-100.

4G3, 5E11, and two monoclonal anti-apo B-100 antibodies, $3 \mathrm{~A} 10$ and $3 \mathrm{~F} 5$, which also do not cross-react with apo B-48 (12). We have now separated apo B-48 and apo B-100 VLDL from five different type III patients under these conditions.

Physical characterization of apo B-48 and apo B-100 VLDL. On paper electrophoresis the apo B-100 VLDL showed a migration similar to the starting VLDL (Fig. 5). The apo B-48 VLDL, on the other hand, remained at the point of application. The particle size distribution is shown in Fig. 6. In the case of the apo B-48 VLDL, particle diameters range from 20 to 260 $\mathrm{nm}$ with a concentration of particles $\sim 90 \mathrm{~nm}$ and a distribution skewed towards particles of larger diameter. The particles in the apo B-100 VLDL show a more restricted distribution, with $80 \%$ of particles having diameters between 55 and $140 \mathrm{~nm}$.

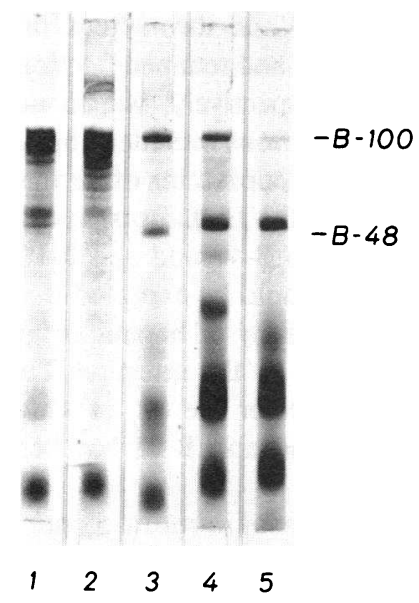

Figure 3. SDS, 3\% polyacrylamide gels stained by Coomassie Blue of the apolipoproteins of fractions from the experiment shown in Fig. 2. Lane 1, starting VLDL; lane 2, fraction retained by $5 E 11$ Sepharose; lane 3 , nonretained fraction after a single passage on $5 \mathrm{E} 11$ Sepharose; lane 4, fraction not retained by $5 E 11$ Sepharose and subsequently not retained following repassage on 5E11 Sepharose; lane 5, fraction not retained by $5 E 11$ Sepharose and subsequently not retained following repassage on $4 \mathrm{G} 3 \mathrm{Se}$ pharose. $80 \mu \mathrm{g}$ of protein was applied to the gels except in the case of the $5 E 11$ nonretained fraction (lane 3), where $40 \mu \mathrm{g}$ protein was applied.

Lipid composition. Analysis of the VLDL and its two affinitypurified fractions by gas-liquid chromatography indicated the presence of the common lipids usually found in VLDL, including free cholesterol, cholesteryl esters with 16- or 18-acyl carbon atoms, triacylglycerols with 48-, 50-, 52- or 54-acyl carbon atoms, and monoacylglycerols, diacylglycerols, and ceramides. These latter three classes of lipids are formed by the digestion of lysophosphatidylcholines, phosphatidylcholines, and sphingomyelins, respectively. The amounts of monoacyl glycerols found were a small percentage of the total lipid in each fraction, but were $\sim 2.5$-fold greater in the apo B-48 VLDL ( $0.33 \%$ of lipid) than in the apo B-100 VLDL ( $0.13 \%$ of lipid).

Table I presents the composition of the three fractions, as the mean of two analyses of each sample. Generally, the duplicate analyses did not differ by more than $1.2 \%$ in any component, and in only one case was the difference as large as $2.1 \%$. There was also good concordance between the values found here for VLDL of normal and type III subjects compared with those reported in the literature $(32,33)$. The major component of each of the fractions was triacylglycerol, which was present in lesser quantities in VLDL and VLDL fractions from type III than in VLDL from normolipidemic subjects. The cholesteryl esters were the second most important component in concentration, and each of the type III fractions was comprised of a greater percentage of cholesteryl esters than was VLDL from normolipidemic subjects. Apo B-48 VLDL was relatively richer in cholesteryl esters and poorer in triacylglycerols than the corresponding apo B-100 VLDL. This cholesteryl ester enrichment of the apo B-48 VLDL was almost entirely due to an enrichment in esters of 18-carbon fatty acids, rather than the minor and almost constant component of 16-carbon fatty acid cholesteryl esters. The two fractions were comprised of similar percentages of unesterified cholesterol, but the apo B-100 VLDL was richer in phospholipids. There was little difference in the proportion of ceramides and diacylglycerols, separated by their acyl chain 


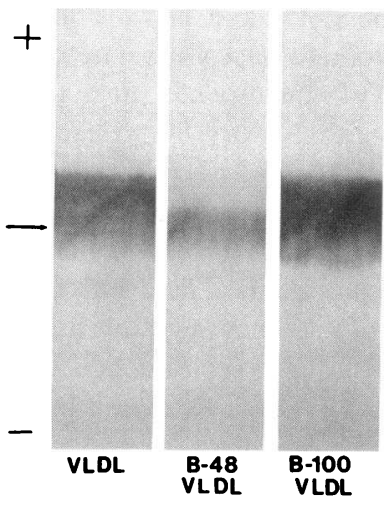

Figure 5. Paper electrophoretogram of VLDL from a type III hyperlipoproteinemic patient and the apo B-48 VLDL and apo B-100 VLDL fractions isolated by affinity chromatography. Approximately $5 \mu \mathrm{g}$ of protein was applied at the point indicated by the arrow. Lipoproteins were detected with Oil Red 0.

length, derived from the phospholipids of the two fractions. However, the apo B-48 VLDL was relatively richer in peaks 34,40 , and 42 , and this may indicate that the apo B-48 VLDL had a higher ratio of sphingomyelins to phosphatidylcholine than the apo B-100 VLDL, or that the greater phospholipid percentage of the apo B-100 VLDL was due to an enrichment in phosphatidylcholines. The present analyses, however, did not directly measure the content of phosphatidylcholines or sphingomyelins in the fractions.

Apolipoprotein composition. On SDS polyacrylamide gel electrophoresis with $10 \%$ acrylamide gels and in the presence of $\beta$-mercaptoethanol (Fig. $7 A$ ), the starting VLDL and the two fractions appeared qualitatively similar. In addition to apo B, a strongly staining band was seen with a molecular weight corresponding to that of apo $\mathrm{E}$ as well as a broad band in the region where apo AII and the apo Cs would migrate. Less intense

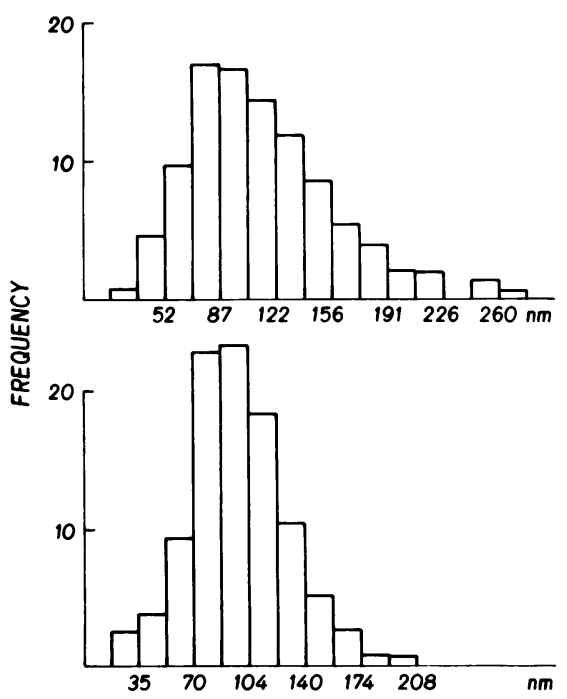

Figure 6. Histogram plot of particle diameter measurements of apo B-48 VLDL (upper) and apo B-100 VLDL (lower) isolated from plasma of type III subjects. Each plot represents the distribution of a thousand particles measured at random from different plates. bands were also seen with apparent molecular weights of $\sim 70,000$ in all fractions, and 45,000 in the VLDL and apo B48 VLDL. On tris-urea polyacrylamide gel (Fig. 7 B) bands corresponding to apo E, apo CI (tentative identification), apo CII, apo CIII-0, apo CIII-1, and apo CIII-2 were seen in all fractions.

The apolipoprotein content of the three VLDL fractions was determined by electroimmunoassay and the results are shown in Table II. In percentage composition the apo B-100 VLDL was almost identical with the starting material. This is not surprising, as in all type III VLDL samples examined apo B-100 has represented the predominant apo B-species (e.g., Fig. 3 , lane 1). In contrast, apo B-48 VLDL was clearly different from the other two fractions. It should be noted that the apo $B$ assay was performed with a polyclonal antiserum raised against LDL (i.e., apo B-100), and therefore the measured apo B content of apo B-48 VLDL may be incorrect. If this were the case, the calculated percentage composition for apo B-48 VLDL with respect to the other apoproteins would also be incorrect. From the absolute values, however, it is clear that in apo B-48 VLDL the ratio of apo $\mathrm{E}$ to the individual apo $\mathrm{C}$ proteins was increased relative to apo B-100 VLDL. As the protein concentration of the apo B-48 VLDL sample was about one-half that of the apo B-100 VLDL sample, the increase in the apo E/apo C ratio of apo B-48 VLDL was due to an enrichment in apo $E$.

\section{Discussion}

Insolubilized monoclonal antibodies against human apo B-100 that show no cross-reactivity against apo B-48 can be used to separate apo B-48-containing particles from apo B-100 particles in the plasma VLDL fraction of patients with type III hyperlipoproteinemia. When care is taken not to overload the immunoadsorbant column, no apo B-100 is detected in the unbound apo B-48 VLDL by either SDS gel electrophoresis or by RIA. The fraction retained by the immunoadsorbants contains apo B-100 as the sole apo B species. While throughout this report we have referred to the nonretained and retained fractions as apo B-48 and apo B-100 VLDL, respectively, we do not exclude the possibility that these two fractions include subpopulations of particles containing only apolipoproteins other than apo B. The ability to separate apo B-100 VLDL from apo B48 VLDL shows that, in the human, apo B-48 and apo B-100 are present on different particles. This would be expected if, as has been suggested, apo B-100 were entirely of hepatic origin and apo B-48 were synthesized uniquely by the intestine. This may not, on the other hand, be the case for the rat, in which hepatic synthesis of both apo B-100 and apo B-48 has been demonstrated (34-36).

This study also illustrates the existence of immunochemical heterogeneity in the apo B-100 VLDL. Subpopulations of apo B-100 VLDL exist in which the antigenic determinants 5E11 and 4G3 are variably expressed. We have previously noted an increased reactivity of VLDL and chylomicrons upon partial delipidation (18). A similar phenomenon had been previously 
Table I. Percent Lipid Composition of VLDL, Apo B-48 VLDL, and Apo B-100 VLDL

\begin{tabular}{|c|c|c|c|c|c|c|}
\hline & \multicolumn{3}{|c|}{ Type III } & \multirow[b]{2}{*}{$\begin{array}{l}\text { Type III* } \\
\text { VLDL }\end{array}$} & \multirow[b]{2}{*}{$\begin{array}{l}\text { Normalł } \\
\text { VLDL }\end{array}$} & \multirow[b]{2}{*}{$\begin{array}{l}\text { Normal§ } \\
\text { VLDL }\end{array}$} \\
\hline & VLDL & B-48 VLDL & B-100 VLDL & & & \\
\hline Unesterified cholesterol & $5.9^{11}$ & 5.9 & 6.7 & 7 & 6 & 4.9 \\
\hline Cholesteryl esters & 26.4 & 36.6 & 24.3 & 25 & 13 & 16.9 \\
\hline Triglycerides & 48.4 & 41.2 & 47.4 & 50 & 61 & 57.0 \\
\hline Phospholipids & 19.2 & 16.2 & 21.6 & 18 & 20 & 21.3 \\
\hline EC/UC $\uparrow$ & 2.7 & 3.7 & 2.2 & 2.1 & 1.3 & 2.1 \\
\hline $\mathrm{EC} / \mathrm{TG}^{* *}$ & 0.55 & 0.89 & 0.51 & 0.50 & 0.21 & 0.30 \\
\hline
\end{tabular}

* From reference 32. ‡ From reference 33. § This study, one sample. " Percent by weight of total lipids (mean of duplicate determinations). T Molar ratio of esterified cholesterol to unesterified cholesterol. ** Weight ratio of cholesterol ester to triglyceride.

described with polyclonal antisera (37). In a recent study using monoclonal antibodies Tsao et al. (38) have reported heterogeneity in the immunochemical expression of apo B in VLDL, IDL, and LDL. Thus, at least part of the observed immunochemical heterogeneity of apo B in VLDL is probably due to the masking of antigenic determinants within the particle. We cannot, however, exclude the possibility that apo B-100 itself is heterogeneous as has been recently suggested (13). It is interesting that all apo B-100 VLDL can be removed by the two monoclonal antibodies $5 \mathrm{E} 11$ and $4 \mathrm{G} 3$. This shows that all apo B-100 VLDL particles express, in an exposed form, the determinants recognized by either the antibodies $5 \mathrm{E} 11$ or $4 \mathrm{G} 3$ or both, implying that the complexity of the immunochemical heterogeneity of VLDL may be limited as far as the expression of the two determinants is concerned. It remains to be seen if the heterogeneity defined by $5 \mathrm{E} 11$ and $4 \mathrm{G} 3$ represents functionally different subpopulations of apo B-100 VLDL particles.

Two recent reports have described the preparation of a fraction of VLDL from type III patients that is enriched in apo B$48(15,16)$. In both cases the subpopulation of VLDL particles with $\beta$ mobility isolated by electrophoresis were subfractionated by gel filtration. The peak that eluted at the void volume was enriched in apo B-48 VLDL, whereas the subsequent fractions were enriched in apo B-100. The apo B-48-enriched fraction
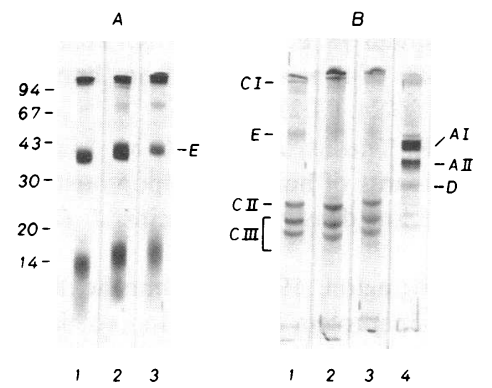

Figure $7.2 \mathrm{mg}$ of type III VLDL was passed sequentially on 5E11 Sepharose and $4 \mathrm{G} 3$ Sepharose. The apolipoproteins of the starting VLDL (lane 1 ), the nonretained fraction (lane 2), and the retained fraction (lane 3) as well as normal high density lipoprotein (lane 4) were analyzed by SDS (Fig. $7 \mathrm{~A}$ ) and tris-urea (Fig. $7 \mathrm{~B}$ ) polyacrylamide gel electrophoresis. $50 \mu \mathrm{g}$ of protein was applied to the gels. In Fig. $7 B$ the positions of apoproteins A-I, A-II, C-II, C-III, D, and E are indicated and apo $\mathrm{C}-\mathrm{I}$ is tentatively identified. showed a similar electrophoretic mobility (characteristic of chylomicrons) and a similar particle size distribution to the apo B48 VLDL described here. Owing to differences in the starting material ( $\beta$-VLDL vs. total VLDL), the physical properties of the apo B-100-enriched fractions cannot be validly compared with those of the apo B-100 VLDL in the present report.

The most striking difference in the apolipoprotein composition between the apo B-48 VLDL and the apo B-100 VLDL fractions was the increased apo E/apo $\mathrm{C}$ ratio of the former as a result of a relative enrichment in apo $E$. In the rat it has been demonstrated that apo $\mathrm{E}$ and the $\mathrm{C}$ apoproteins can influence lipoprotein uptake by the liver $(39,40)$. In addition to the apoproteins shown in Table II, trace amounts of apo AIV, apo D, and albumin were detected by a semi-quantitative RIA in both the apo B-48 and apo B-100 VLDL fractions (unpublished results). Differences in the lipid composition of the two fractions have also been noted. Apo B-48 VLDL was characterized by lower content of phospholipids and triglycerides and higher content of cholesteryl esters compared with apo B-100 VLDL. The relative enrichment in cholesteryl esters of apo B-48 VLDL was also apparent from the values of the ratios of esterified cholesterol to unesterified cholesterol, and cholesteryl esters to triglycerides. These observations are consistent with the net transfer of cholesteryl esters from high density lipoproteins to

Table II. Apoprotein Composition of Type III VLDL, Apo B-48 $V L D L$, and Apo B-100 VLDL

\begin{tabular}{lcll}
\hline & VLDL & Apo B-48 VLDL & Apo B-100 VLDL \\
\hline Apo AI & $4.8^{*}$ & 0 & 0.3 \\
Apo AII & 7.6 & 0 & Trace \\
Apo B & $237.2(57) \ddagger$ & $5.2(34)$ & $11.8(55)$ \\
Apo CI & $29.3(7)$ & $1.4(9)$ & $1.6(7)$ \\
Apo CII & $19.7(5)$ & $1.1(7)$ & $1.1(5)$ \\
Apo CIII & $63.7(15)$ & $2.3(15)$ & $3.3(15)$ \\
Apo E & $61.5(15)$ & $5.2(34)$ & $3.6(17)$
\end{tabular}

* Apoprotein concentration, $\mathrm{mg} / 100 \mathrm{ml}$.

$¥$ Percent of total measured apoproteins in parentheses. 
chylomicrons, as noted in vitro $(41,42)$, and provide support for the existence of such a pathway in vivo, which is thought to be important in the reverse transport of cholesterol to the liver. While apo B-48 was enriched in cholesteryl esters relative to apo B-100 VLDL, the apo B-100 VLDL itself had relatively more cholesteryl esters and fewer triglycerides than did normal VLDL. This suggests that both the apo B-100 VLDL and the apo B-48 VLDL contributed to the hypercholesterolemia and to the characteristic ratio of VLDL cholesterol to total plasma triglyceride of type III hyperlipoproteinemia. In all cases, VLDL was isolated from plasma taken from type III patients who had fasted overnight. Thus, despite a prolonged residence time in plasma, during which exchanges of both lipids and apolipoproteins occurred between lipoprotein fractions, the apo B-48 VLDL nevertheless maintained a lipid and apolipoprotein composition distinct from that of the rest of the VLDL. We have confirmed that the differences between apo B-48 VLDL and apo B-100 VLDL in their respective apoprotein and lipid compositions and electrophoretic mobilities were not artifacts resulting from the acidic conditions to which the apo B-100 VLDL fraction had been subjected (unpublished results).

The accumulation of chylomicrons, VLDL, and IDL in patients showing type III hyperlipoproteinemia has generally been ascribed to a delayed clearance from plasma of those lipoproteins and especially of chylomicron remnants $(43,44)$. The defect in catabolism of remnants in type III subjects is, at least in part, due to the presence of the apo E-2 isoform $(2,3)$, which is poorly recognized by cell surface receptors $(4,5)$ and which shows retarded intravascular metabolism (45). Since chylomicron remnants are cleared from plasma by the liver (46), which contains apo E receptors (47), we can imagine that the rate of input of chylomicron remnants and their lipids into the liver is reduced in the type III subject. This might reduce the feedback inhibition of hepatic cholesterol synthesis, as has been observed in fibroblasts (48), and cause overproduction and secretion of cholesterol and apo B-100, possibly explaining both the overproduction of VLDL and IDL (9) and the abnormal cholesterol-enriched composition of the apo B-100 VLDL in these subjects.

In summary, we have presented a method to separate completely the VLDL from the plasma of type III hyperlipidemic patients into two fractions that have apo B-48 and apo B-100 as their sole apo B species. The characterization of the two fractions has shown them to be different in a number of chemical and physical properties. The ability to prepare apo B-48 VLDL free of apo B-100 should facilitate experiments to determine if apo B-48 is recognized by cell surface receptors as well as studies of the comparative intravascular metabolism of apo B-48 and apo B-100 VLDL.

\section{Acknowledgments}

We wish to thank Dr. Walter McConathy for providing antisera, Mr. Jim Fesmire for expert assistance with the electroimmunoassays, and Dr. Marc Cantin and Christian Charbonneau for their aid with the electron microscopy. We appreciate the help of Lucie Boulet and Josée Gingras with the paper electrophoresis and Denise Brossard, Hélène
Mailloux, and Suzanne Quidoz in taking blood samples. We are indebted to Louise Lalonde for excellent secretarial assistance.

This study was supported by grants from the Medical Research Council of Canada (PG-27) and from the Quebec Heart Foundation.

\section{References}

1. Fredrickson, D. S., J. L. Goldstein, and M. S. Brown. 1978. The familial hyperlipoproteinemias. In The Metabolic Basis of Inherited Disease. J. B. Stanbury, J. B. Wyngaarden, and D. S. Fredrickson, editors. McGraw-Hill, Inc., New York. Fourth ed. 604-655.

2. Utermann, G., M. Hess, and M. Steinmetz. 1977. Polymorphism of apolipoprotein $\mathrm{E}$ and occurrence of dysbetalipoproteinemia in man. Nature (Lond.). 269:604-607.

3. Zannis, V. I., and J. L. Breslow. 1980. Characterization of a unique human apo $\mathrm{E}$ variant associated with type III hyperlipoproteinemia. J. Biol. Chem. 255:1759-1762.

4. Schneider, W. J., P. T. Kovanen, M. S. Brown, J. L. Goldstein, G. Utermann, W. Weber, R. J. Havel, L. Kotite, J. P. Kane, T. L. Innerarity, and R. W. Mahley. 1981. Familial dysbetalipoproteinemia: abnormal binding of mutant apoprotein $\mathrm{E}$ to lipoprotein receptors of human fibroblasts and membranes from liver and adrenal of rats, rabbits, and cows. J. Clin. Invest. 68:1075-1085.

5. Rall, S. C., K. H. Weisgraber, T. L., Innerarity, and R. W. Mahley. 1982. Structural basis for receptor binding heterogeneity of apolipoprotein E from type III hyperlipoproteinemic subjects. Proc. Natl. Acad. Sci. USA. 79:4696-4700.

6. Curry, M. D., W. J. McConathy, P. Alaupovic, J. H. Ledford, and M. Popovic. 1976. Determination of human apolipoprotein E by electroimmunoassay. Biochim. Biophys. Acta. 439:413-425.

7. Utermann, G., K. H. Vogelberg, A. Steinmetz, W. Schoenborn, N. Pruin, M. Jaeschke, M. Hees, and H. Canzler. 1979. Polymorphism of apolipoprotein E. II. Genetics of hyperlipoproteinemia type III. Clin. Genet. 15:37-62.

8. Hazzard, W. R., G. R. Warnick, G. Utermann, and J. J. Albers. 1981. Genetic transmission of isoapolipoprotein $E$ phenotypes in a large kindred: relationship to dysbetalipoproteinemia and hyperlipidemia. Metab. Clin. Exp. 30:79-88.

9. Berman, M., M. Hall III, R. I. Levy, S. Eisenberg, D. W. Bilheimer, R. D. Phair, and R. H. Goebel. 1978. Metabolism of apo B and apo C lipoproteins in man: kinetic studies in normal and hyperlipoproteinemic subjects. J. Lipid Res. 19:38-56.

10. Reardon, M. F., M. E. Poapst, and G. Steiner. 1982. The independent synthesis of intermediate density lipoproteins in type III hyperlipoproteinemia. Metab. Clin. Exp. 31:421-427.

11. Kane, J. P., D. A. Hardman, and H. E. Paulus. 1980. Heterogeneity of apolipoprotein B: isolation of a new species from human chylomicrons. Proc. Natl. Acad. Sci. USA. 77:2365-2369.

12. Marcel, Y. L., M. Hogue, R. Theolis, Jr., and R. M. Milne. 1982. Mapping of antigenic determinants of human apolipoprotein B using monoclonal antibodies against low density lipoproteins. J. Biol. Chem. 257:13165-13168.

13. Curtiss, L. K., and T. S. Edgington. 1982. Immunochemical heterogeneity of human plasma apolipoprotein B. I. Apolipoprotein B binding of mouse hybridoma antibodies. J. Biol. Chem. 257:1521315221 .

14. Malloy, M. J., J. P. Kane, D. A. Hardman, R. L. Hamilton, and K. B. Dalal. 1981. Normotriglyceridemic abetalipoproteinemia: absence of the B-100 apolipoprotein. J. Clin. Invest. 67:1441-1450.

15. Fainaru, M., R. W. Mahley, R. L. Hamilton, and T. L. Innerarity. 1982. Structural and metabolic heterogeneity of $\beta$-very low density li- 
poproteins from cholesterol-fed dogs and humans with Type III hyperlipoproteinemia. J. Lipid Res. 23:702-714.

16. Kane, J. P., G. C. Chen, R. L. Hamilton, D. A. Hardman, M. J. Malloy, and R. J. Havel. 1983. Remnants of lipoproteins of intestinal and hepatic origin in familial dysbetalipoproteinemia. Arteriosclerosis. 3:47-56.

17. Milne, R. W., R. Theolis, Jr., R. B. Verdery, and Y. L. Marcel. 1983. Characterization of monoclonal antibodies against human low density lipoprotein. Arteriosclerosis. 3:23-30.

18. Marcel, Y. L., P. Douste-Blazy, and R. W. Milne. 1983. Monoclonal antibodies against apolipoproteins: applications to the characterization and quantitation of human apo B. In NHLBI Workshop on Apolipoprotein Methods. K. Lippel, editor. U. S. Department of Health Services, Bethesda, MD. 414-424.

19. Bouthillier, D., C. F. Sing, and J. Davignon. 1983. Apolipoprotein E phenotyping with a single gel method. Application to the study of informative matings. J. Lipid Res. 24:1060-1069.

20. Havel, R. J., H. A. Eder, and J. H. Bragdon. 1955. The distribution and chemical composition of ultracentrifugally separated lipoproteins in human serum. J. Clin. Invest. 34:1345-1355.

21. March, S. C., I. Parikh, and P. Cuatrecasas. 1974. A simplified method for cyanogen bromide activation of agarose for affinity chromatography. Anal. Biochem. 60:149-152.

22. Curry, M. D., P. Alaupovic, and C. A. Suenram. 1976. Determination of apolipoprotein A and its constitutive A-I and A-II polypeptides by separate electroimmunoassays. Clin. Chem. 22:315-322.

23. Curry, M. D., A. Gustafson, P. Alaupovic, and W. J. McConathy. 1978. Electroimmunoassay, radioimmunoassay, and radial immunodiffusion assay elevated for quantification of human apolipoprotein B. Clin. Chem. 24:280-286.

24. Curry, M. D., W. J. McConathy, J. D. Fesmire, and P. Alaupovic. 1981. Quantitative determination of apolipoproteins C-I and C-II in human plasma by separate electroimmunoassays. Clin. Chem. 27:543548.

25. Curry, M. D., W. J. McConathy, J. D. Fesmire, and P. Alaupovic. 1980. Quantitative determination of human apolipoprotein C-III by electroimmunoassay. Biochim. Biophy. Acta. 617:503-513.

26. Kuksis, A., J. J. Myher, L. Marai, and K. Geher. 1975. Determination of plasma lipid profiles by automated gas chromatography and computerized data analysis. J. Chromatogr. Sci. 13:423-430.

27. Weber, K., and M. Osborn. 1969. The reliability of molecular weight determinations by dodecyl sulfate polyacrylamide gel electrophoresis. J. Biol. Chem. 244:4406-4412.

28. Kane, J. P. 1973. A rapid electrophoretic method for identification of subunit species of apoproteins in serum lipoproteins. Anal. Biochem. 53:350-364.

29. Lees, R. S., and F. T. Hatch. 1963. Sharper separation of lipoprotein species by paper electrophoresis in albumin-containing buffer. J. Lab. Clin. Med. 61:518-528.

30. Chapman, M. J., and S. Goldstein. 1976. Comparison of the serum low density lipoprotein and of its apoprotein in the pig, rhesus monkey and baboon with that in man. Atherosclerosis. 25:267-291.

31. Lowry, O. H., N. J. Rosebrough, A. L. Farr, and R. J. Randall. 1951. Protein measurement with the folin phenol reagent. J. Biol. Chem. 193:265-275.

32. Kuksis, A., J. J. Myher, K. Geher, W. C. Breckenridge, G. J. L. Jones, and J. A. Little. 1981. Lipid class and molecular species interrelationships among plasma lipoproteins of normolipemic subjects. J. Chromatogr. 224:1-23.
33. Kuksis, A., J. J. Myher, K. Geher, W. C. Breckenridge, and J. A. Little. 1982. Lipid class and molecular species interrelationships among plasma lipoproteins of type III and type IV hyperlipemic subjects. J. Chromatogr. 230:231-252.

34. Sparks, C. E., O. Hnatiuk, and J. B. Marsh. 1981. Hepatic and intestinal contribution of two forms of apolipoprotein B to plasma lipoprotein fractions in the rat. Can. J. Biochem. 59:693-699.

35. Bell-Quint, J., T. Forte, and P. Graham. 1981. Synthesis of two forms of apolipoprotein B by cultured rat hepatocytes. Biochem. Biophys. Res. Commun. 99:700-706.

36. Wu, A.-L., and H. G. Windmueller. 1981. Variant forms of plasma apolipoprotein B: hepatic and intestinal biosynthesis and heterogeneous metabolism in the rat. J. Biol. Chem. 256:3615-3618.

37. Schonfeld, G., W. Patsch, B. Pfleger, J. L. Witzum, and S. W. Weidman. 1979. Lipolysis produces changes in the immunoreactivity and cell reactivity of very low density lipoproteins. J. Clin. Invest. 64:1288-1297.

38. Tsao, B. P., L. K. Curtiss, and T. Edgington. 1982. Immunochemical heterogeneity of human plasma apolipoprotein B. II. Expression of apolipoprotein B epitopes on native lipoproteins. J. Biol. Chem. 257:15222-15228.

39. Shelburne, F., J. Hanks, W. Meyers, and S. Quarfordt. 1980. Effect of apoproteins on hepatic uptake of tryglyceride emulsions in the rat. J. Clin. Invest. 65:652-658.

40. Windler, E., Y.-S. Chao, and R. J. Havel. 1980. Regulation of the hepatic uptake of triglyceride-rich lipoproteins in the rat. Opposing effects of homologous apolipoprotein $\mathrm{E}$ and individual $\mathrm{C}$ apoproteins. J. Biol. Chem. 255:8303-8307.

41. Marcel, Y. L., C. Vezina, B. Teng, and A. Sniderman. 1980. Transfer of cholesterol esters between human high density lipoproteins and triglyceride-rich lipoproteins controlled by a plasma protein factor. Atherosclerosis. 35:127-133.

42. Marcel, Y. L., C. Vezina, and R. W. Milne. 1983. Cholesteryl ester and apolipoprotein $\mathrm{E}$ transfer between human high density lipoproteins and chylomicrons. Biochim. Biophys. Acta. 750:411-417.

43. Chait, A., W. R. Hazzard, J. J. Albers, R. P. Kushwaha, and J. D. Brunzell. 1978. Impaired very low density lipoprotein and triglyceride removal in broad beta disease: comparison with endogenous hypertriglyceridemia. Metab. Clin. Exp. 27:1055-1065.

44. Hazzard, W. R., and E. L. Bierman. 1976. Delayed clearance of chylomicron remnants following Vitamin-A-containing oral fat loads in broad-beta disease (type III hyperlipoproteinemia). Metab. Clin. Exp. 25:771-801.

45. Gregg, R. E., L. A. Zech, E. J. Schaefer, and H. B. Brewer. 1981. Type III hyperlipoproteinemia: defective metabolism of an abnormal apoprotein E. Science (Wash. DC). 211:584-586.

46. Sherill, B. C., and J. M. Dietschy. 1978. Characterization of the sinusoidal transport process responsible for uptake of chylomicrons by the liver. J. Biol. Chem. 253:1859-1867.

47. Sherill, B. C., T. L. Innerarity, and R. W. Mahley. 1980. Rapid hepatic clearance of the canine lipoproteins containing only the $E$ apoprotein by a high affinity receptor: identity with the chylomicron remnant transport process. J. Biol. Chem. 255:1804-1807.

48. Gianturco, S. H., A. M. Gotto, Jr., S.-L. Huang, J. B. Karlin, A. H. Y. Lin, S. C. Prasad, and W. A. Bradley. 1982. Apolipoprotein E mediates uptake of Sf $100-400$ hypertriglyceridemic very low density lipoproteins by the low density lipoprotein receptor pathway in normal human fibroblasts. J. Biol. Chem. 258:4526-4533. 